\title{
RADIATION PAIN THRESHOLDS IN RELATION TO SKIN TEMPERATURES
}

\author{
BY \\ J. W. BEATTIE AND A. WOODMANSEY \\ From the Department of Clinical Medicine, University of Leeds, \\ the General Infirmary at Leeds, and Meanwood Park Hospital, Leeds
}

(RECEIVED FOR PUBLICATION MARCH 21, 1955)

The marked analgesic effects experienced by rheumatic patients in this Unit after the administration of intravenous infusions of adrenocorticotropic hormone (ACTH) stimulated our interest in pain thresholds. To investigate this, it was decided to analyse the alterations in the integumentary pain threshold produced by the various drugs commonly used as analgesic, suppressive, or supportive agents for arthritic patients, since numerous articles in the literature had reported that such analgesics could be thus assessed (Slaughter and Gales, 1942; Andrews, 1942, 1943a; Chapman, Arrowood, and Beecher, 1943; Slaughter, Gales, and Johnson, 1944; Flodmark and Wramner, 1945; Leduc and Slaughter, 1945; Scott and Chen, 1946a, 1946b; Scott, Robbins, and Chen, 1946; Gross, Holland, and Schueler, 1948).

Although pain in the human integument may be produced by either mechanical, chemical, electrical, or thermal stimuli, after experimentation with various devices, a modification of the thermal radiation technique of Hardy, Wolff, and Goodell (1940), used by the investigators above, was finally adopted. This technique appeared to offer the advantages of a measurable stimulus and an endpoint reasonably easily detected by the subject.

The subjective nature of pain has resulted in some misunderstanding regarding measurement. This has arisen through confusion of the perception of a "painful sensation" with the emotional and other reactions that follow the actual perceptual experience. The emotional accompaniments will depend upon the personality of the subject, but the actual perception of pain should depend only on the application of a threshold stimulus, less intense stimuli not evoking the pain sensation. This study is concerned with the pain perception threshold as represented by the verbal report of pain and not the pain reaction threshold, or the maximum tolerance of pain.
The initial experiments on certain rheumatoid arthritis patients and on the authors using corticotrophin infusions, aspirin, pethidine, and amphetamine produced discordant results. The ACTHtreated patients were experiencing feelings of warmth and flushing, while the authors felt cold after pethidine and amphetamine. Despite the extensive use of the Hardy, Wolff, and Goodell (1940) technique for analgesic testing and pain threshold estimations (vide infra), no critical consideration of skin temperature could be found in the literature before 1951, except the passing references of the originators. Whyte (1951), using low intensity of radiation and thus long exposures, showed that the sensations of prick-pain and of intolerable pain occurred when the skin temperature reached certain absolute values, even when different intensities of heat and different starting temperatures were used.

It was decided, therefore, to investigate the radiation pain thresholds in relation to initial skin temperatures. In a constant environment, skin temperature is conditioned by various factors, including blood flow, insensible sweating, thickness of skin, and conductivity. It did not appear necessary, therefore, to attempt to study these factors individually.

\section{Method}

A beam of light from a 500-watt lamp with compact spiral filament supplied with a rheostatically fixed current of $1.8 \mathrm{amp}$. was focused by a condensing lens through a circular aperture 1 inch in diameter, with a manually operated shutter, on to the skin of the forearm, or occasionally on to the dorsum of the hand or the forehead. The radiant energy of the instrument measured by a water calorimeter specially designed for the purpose was found to be $140 \mathrm{mg}$. calories per sq. $\mathrm{cm}$. per sec. (equivalent to 8.4 pyrons). This intensity was found by trial to permit both definite recognition of the end-point and a suitable length of exposure. In all but the earliest experiments, where powdered charcoal regularly renewed 
was employed, the skin was blackened with moistened carbon black and allowed to dry.

Blackening was found necessary to absorb all the radiation in order to obtain more consistent results. We preferred to use the forearm as we assumed that the patients would be less likely to give early and false signals than if the forehead were used. Hardy, Wolff, and Goodell (1952a) have confirmed that the pain threshold is roughly uniform over most of the body surface.

The duration of the stimulus was measured by stopwatch from the raising of the shutter to the patient's report that the pain threshold had been reached. The attainment of the threshold so signalled by the subject is indicated by the first sensation of pain and not the maximum amount of pain that can be tolerated. It is preceded by a sensation of heat, which increases in intensity to attain suddenly the sharp or pricking pain regarded as the "end-point".

Hardy and others (1940) used a fixed exposure to the forehead of $3 \mathrm{sec}$., the voltage applied to the lamp being altered each time until the threshold was found. Thus several applications of the beam were required to produce one threshold record. In our modification, each exposure provided one record.

In actual tests, after the subjects had become familiar with the routine, four different but adjacent areas of the skin were separately stimulated each time and the average of the four results was taken as the pain threshold value for that particular time. The skin temperature of the four sites was also measured immediately before the radiation and the results averaged. For this purpose an electric skin thermometer, based on the bridge principle, with a thermistor probe, was employed. The observations were made at not less than 15 -min. intervals; preliminary skin temperature tests carried out before and 10 minutes after the pain stimulus showed a complete return to the previous level. No flare or sign of visible sweating was apparent when tests were made without blackening.

\section{Results}

The threshold for radiation pain has been defined, as by Hardy, Wolff, and Goodell, as the quantum of

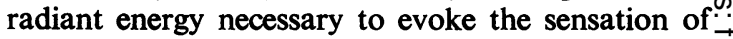
prick-pain. However, for simplicity, the absolute $\overrightarrow{\bar{N}}$ values for the pain thresholds are not presented in the graphs. They can be found from the product of the duration of exposure and the constant of the instrument. A distinction must be made between $\mathbb{Q}$ the "apparent pain thresholds", as obtained in this manner, and the actual pain thresholds which ${ }^{\infty}$ represent the former suitably corrected for initial $\vec{O}$ skin temperature.

\section{Group 1 (Patients)}

(A) In this early series, four patients (Cases 1-4) were taken at random; they were not particularly good subjects. The test areas of the forearm were

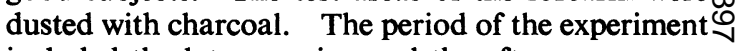
included the late morning and the afternoon.

The first experience of one subject, Case 1 , aged $72, \stackrel{\rightarrow}{\rightarrow}$ is illustrated in Fig. 1. After midday when the skin temperature fell somewhat the apparent pain threshold rose; later the converse occurred.

(B) For the same four patients the effect of $15 \mathrm{gr}$. 뜸 aspirin on the pain perception threshold in cos- $\overrightarrow{-}$ relation with skin temperature was measured. TRe c drug was given in powder form suitably disguised. In these and all subsequent experiments moistened carbon black was used.

In no case was there any marked or sustained increase in threshold level. The results in Caseso 1 and 2 are shown in Fig. 2 (opposite). Here the $\stackrel{\mathbb{D}}{2}$ early apparent increases in pain thresholds are $\overrightarrow{\vec{O}}$ accompanied by decreases in skin temperatures.

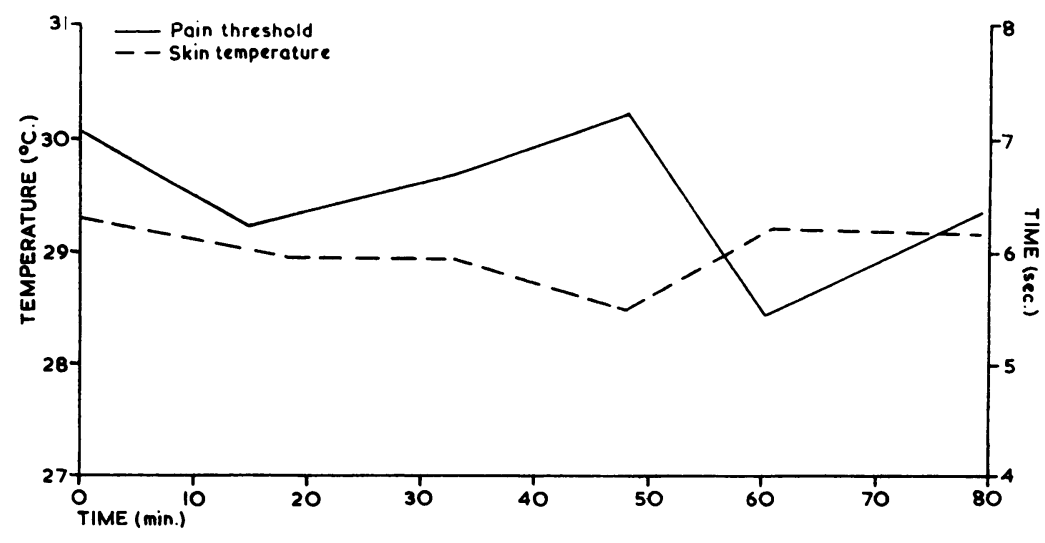

Fig. 1.-Case 1, showing variation of apparent pain threshold and skin temperature of forearm. 

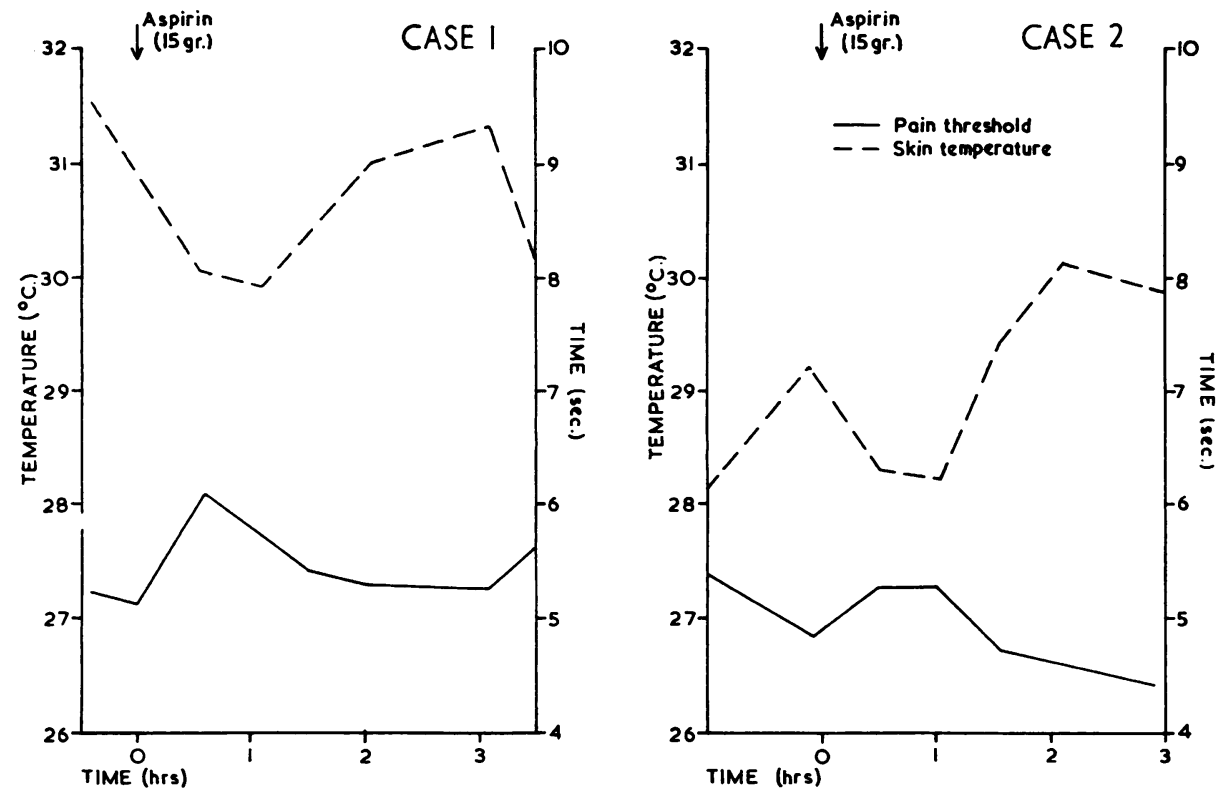

Fig. 2.-Cases 1 and 2, showing alteration of skin temperature and apparent pain threshold of forearm following $15 \mathrm{gr}$. aspirin.

(C) With the same four subjects the effect of morphine sulphate $\frac{1}{6}$ gr. by subcutaneous injection was measured.

In three patients there was an increase in the apparent pain threshold, but there was some fall in the skin temperature at the same time. The fourth subject revealed no elevation in the apparent pain threshold.

\section{Group 2 (Observers)}

(A) In these experiments the three observers (J.W.B., A.W., and B.G.L.), working in pairs, measured the pain thresholds and skin temperatures of the third member. An inverse relationship between the apparent pain threshold levels and the skin temperatures was evident.

(B) The effect of aspirin on the same three observers was measured on two different occasions in one month (October 10 and 23, 1952), using 15 gr. and 20 gr. respectively.

Fig. 3 indicates very strikingly the inverse relationship between the apparent pain threshold and the skin temperature in two of the observers.

On the second occasion two test sites (forearm and dorsum) were utilized. In one subject (B.G.L.) no gross alteration in the pain threshold occurred on either site; in another (J.W.B.) the forearm threshold remained constant while the dorsum apparent threshold rose; in the third (A.W.) the two sites showed opposite changes. There was an overall

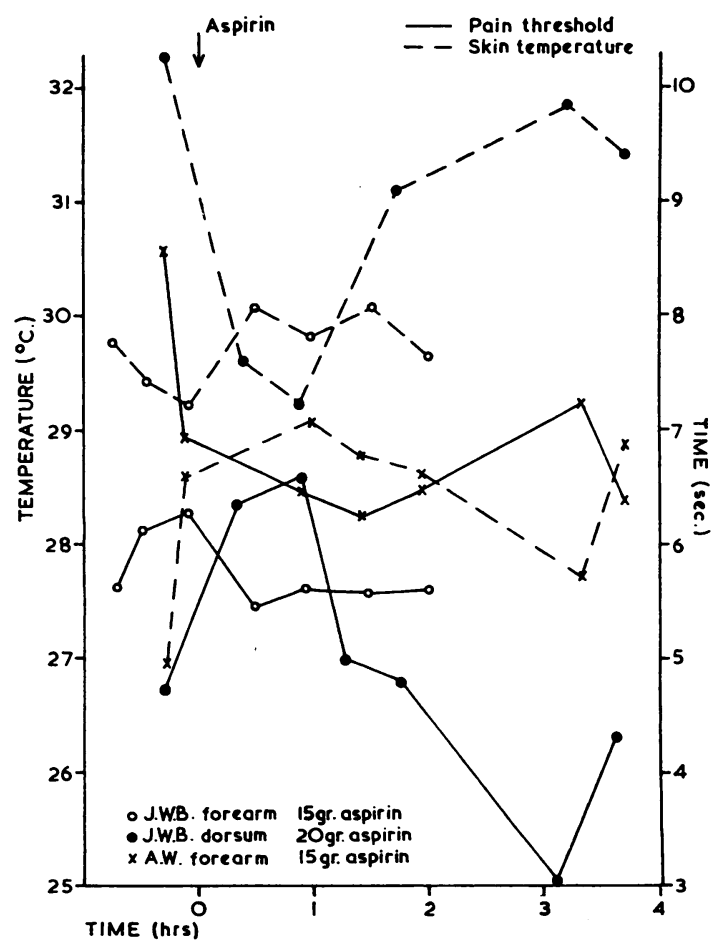

Fig. 3.-Alteration of skin temperature and apparent pain threshold in two observers (J.W.B. and A.W.) after aspirin.

inverse relationship between apparent pain thresholds and skin temperatures. 
Subsequently (February 25, 1953), the two authors (J.W.B. and A.W.) were tested again after receiving 20 gr. aspirin. No change occurred in the forearm thresholds, but the dorsum apparent threshold was slightly elevated in one; nevertheless, the skin temperature correlated inversely with these alterations. This experiment indicated how difficult it would be to attribute to the aspirin any effect on the pain threshold, since the control period showed such great variations (also correlated inversely with temperature).

(C) The two authors received 10 and $20 \mathrm{gr}$. amphetamine sulphate respectively. The only change in the apparent pain threshold was a lowering in one instance, in which the skin temperature rose (J.W.B.). This experience is demonstrated in Fig. 4.

(D) The effect of antihistamines was also investigated. Phenindamine hydrogen tartrate (Thephorin, Roche) was administered on two occasions to one subject (J.W.B.) in doses of $50 \mathrm{mg}$. and $75 \mathrm{mg}$., and to another (A.W.) in doses of $75 \mathrm{mg}$. and $100 \mathrm{mg}$. Tests were carried out on the forearm and dorsum of the hand. Subsequently the effect of $300 \mathrm{mg}$. mepyramine maleate (Anthisan, May and Baker) was measured on the forehead, forearm, and dorsum of hand for each subject.
A total of fourteen tests, therefore, was carried $\frac{}{\Phi}$ out. The inverse relationship with skin temperature $\leftrightharpoons$ was not clearly maintained, and on many occasions there was an indication of increased pain sensitivity, especially after Anthisan.

Group 3 (Technicians).-Two technicians without previous experience and from another laboratory $\frac{\bar{c}}{\bar{T}}$ were given morphine sulphate $\frac{1}{6}$ gr. by subcutaneous $\mathbb{Q}$ injection. Tests were made on forearm and forehead in each case. The subjects were somewhat apprehensive, nausea and drowsiness were experi- $\vec{\circ}$ enced, and there was difficulty in concentration and some apathy. There appeared to be a real increase ${ }_{\mathcal{L}}^{\omega}$ in pain threshold, for here the inverse relationship with skin temperature was not strictly followed.

Group 4 (Authors). - In this group of experiments on the authors, the temperature of the forearm was deliberately and artificially altered. This was done 을 by keeping one arm continually immersed first in iced water and then in hot water, to produce indirect vasodilatation and constriction in the other $\underset{\mathbb{\Phi}}{\mathbb{D}}$ (test) arm. An almost perfect correlation between $\stackrel{\Phi}{3}$ the apparent pain threshold level and the skin temperature was obtained (Fig. 5).

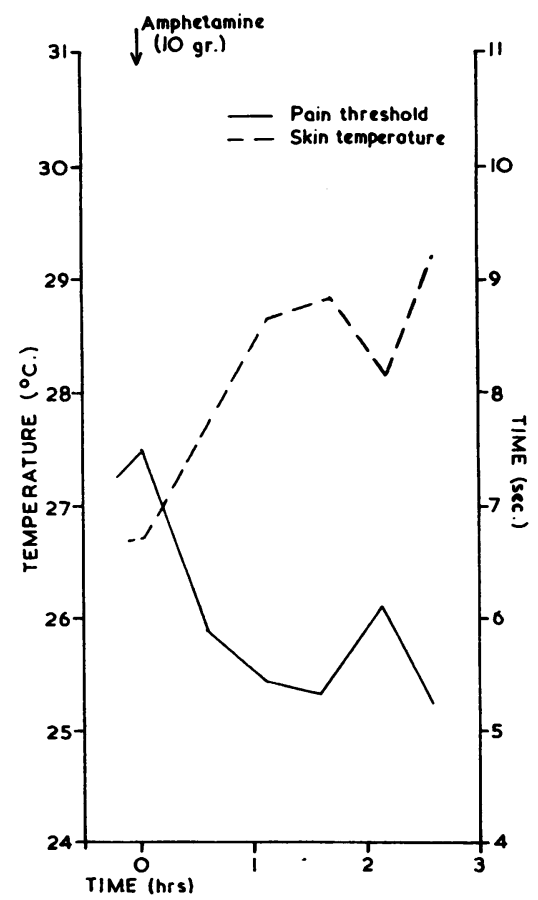

Fig. 4.-Alteration of skin temperature and apparent pain threshold of forearm after $10 \mathrm{gr}$. amphetamine. (Author J.W.B.)
Fig. 5.-Variation of apparent pain threshold after artificial alteration of skin temperature of forearm. (Author J.W.B.)

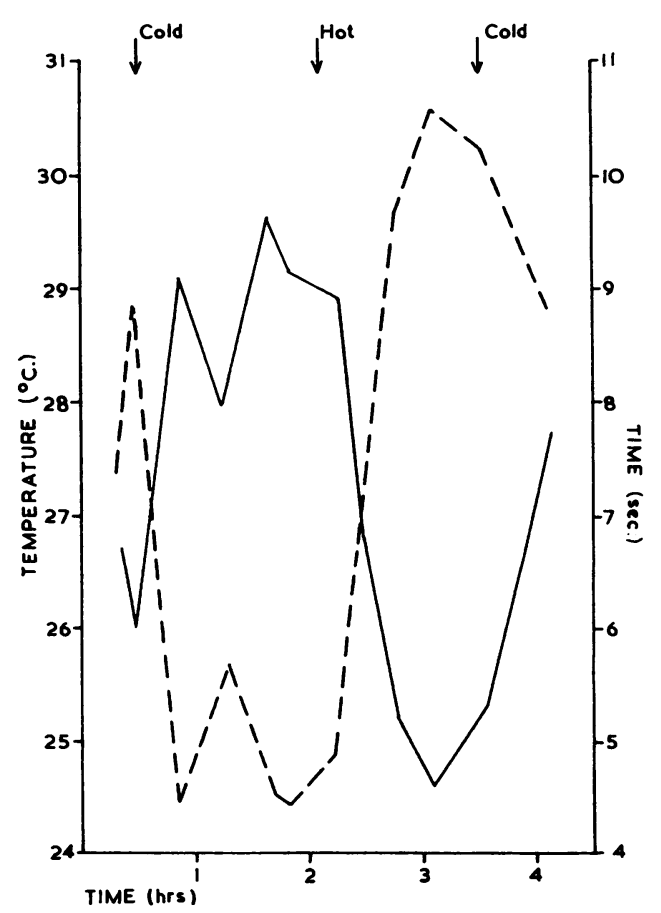




\section{Statistical Analysis}

In the statistical examination of the results, a preliminary regression analysis for the experiments in which "artificial heating" of the tissues was used to vary skin temperatures gave an estimate of the skin temperature coefficient of $-0.62 \mathrm{sec}$. per ${ }^{\circ} \mathrm{C}$. All pain thresholds recorded in all experiments were then compensated for varying skin temperatures, using this temperature coefficient, and the compensated thresholds were recorded on time charts and scrutinized. The time charts showed no regular pattern of variation after the administration of the drugs, and the irregularity of their patterns suggested the following method of analysis:

It was assumed that the pain threshold could be explained as a linear function of skin temperature, plus a constant depending upon the identity of the subject of the experiment, plus a constant depending upon the drug administered, plus a constant depending upon the part of the body to which the radiation was administered, plus a random term. The appropriate equation was fitted to the data using conventional multiple regression methods.

It was apparent that there were significant interpersonal differences between the different subjects. There was not, however, a significant difference between the mean thresholds of the rheumatoid arthritis patients and the rest. The results obtained at different sites on the body were not significantly different from one another. In view of the complications introduced into the analysis by the finding of significant day-to-day variations, it was decided to use a simpler and more obvious method of estimating the effects of each drug, which could not be explained from skin temperature, using the means of the compensated pain threshold values, already calculated, before and after administering the drug, the difference being taken as a measure of the effect of the drug. It was decided to combine the differences before and after administration on the different occasions on which the same drug was used in order to determine the mean effect of the drug on all occasions. Weighted means were estimated, the weighting being determined by the number of readings used before the drug was administered and also by the different quantities of the drug employed on different occasions. Estimates of the standard error of these weighted differences were prepared and these standard errors were used to provide approximate tests of the significance of the differences. Lower pain thresholds, i.e. smaller quanta of radiant energy, than would be expected after compensating for the corresponding initial skin temperatures were produced by aspirin, amphetamine, and Thephorin at the 5 per cent. level, and by Anthisan at the 1 per cent. level of significance. The only analgesic effects obtained followed the administration of morphia, significant at the 5 per cent. level.

\section{Discussion}

These experiments show that alterations in the apparent radiation-pain threshold of the skin are correlated with changes in the skin temperature. In most cases elevations were accompanied by decreases in the skin temperature. This effect must be taken into consideration before any apparent elevations of the threshold following the administration of various drugs are accepted.

The radiation technique of Hardy, Wolff, and Goodell (1940) has been extensively employed in the investigation of pain thresholds by many authors (including Andrews, 1943b; Chapman and Jones, 1944; Bigelow, Harrison, Goodell, and Wolff, 1945; Chapman, Finesinger, Jones, and Cobb, 1947; Schilling and Musser, 1948; 1949a, b; Hazouri and Mueller, 1950; McMurray, 1950; Clausen and King, 1950; Hemphill, Hall, and Crookes, 1952; Hall and Stride, 1954), but in no case have the authors indicated any inquiry regarding the corresponding initial skin temperatures. Thus only apparent threshold values have been obtained.

Despite the uniformity of the pain threshold as claimed by Schumacher, Goodell, Hardy, and Wolff (1940), Schamp and Schamp (1946) found a significant variability in different persons and also in the same person over a period of time, similar to that reported by Slaughter and Wright (1944). Kutscher and Chilton (1951) also found the threshold measurements "asymmetrically distributed and different among the subjects tested". Hall (1953) referred to the important effect of the variable composite factor-attitude. Our experience has also shown significant interpersonal and day-to-day differences. No variation in respect of the three separate sites utilized was observed. Furthermore, we were not able to discover any significant difference between the actual pain thresholds of the four rheumatoid arthritic patients and a normal group composed of the authors and technicians.

Many other investigators have been unsuccessful with this method in the assessment of analgesics. Ivy, Goetzel, and Burrill (1944) found a lowered pain perception threshold in about half of their subjects after $16 \mathrm{mg}$. morphine. Sonnenschein and Ivy (1949), with a similar technique, Birren, Schapiro, and Miller (1950), Kuhn and Bromiley (1951), and Whyte (1951), using aspirin, and Slaughter (1944), Chapman and Jones (1944), Dodds, Lawson, Simpson, and Williams (1945), Thorp (1946), Kuhn and Bromiley (1951), and Whyte (1951) using morphine, were also unable to substantiate the elegant parabolic curves of percentage increases in the radiation pain thresholds (actually apparent thresholds) presented by Wolff, Hardy, and Goodell (1940, 1941, 1942). Denton and Beecher (1949) found gross inconsistencies between drugs recognized clinically as effective analgesics; they observed in 
some cases elevation of the pain threshold after saline and in others lowering after morphine. Kibler and Schnaper (1950) and Kutscher and Chilton (1952) observed no alteration after $1 \mathrm{~g}$. procaine intravenously or the antihistamines (Pyribenzamine and Antistine) respectively.

Even Hardy and Cattell (1950) after testing 160 medical students over a period of 3 years with aspirin, codeine, and pethidine, found that their results "did not reveal any significant influence on the pain threshold measurements. Certain subjects receiving aspirin or the other agents exhibited a characteristic elevation of threshold but in others it was depressed from 10 to 20 per cent." In the face of these conflicting observations, however, they preferred to accept the results obtained without placebo controls by the three trained observers (Hardy, Wolff, and Goodell), and "concluded that untrained subjects, even of high intelligence, cannot be used successfully to measure the thresholdraising effects of aspirin, codeine, and meperidine (pethidine) in the amounts given".

We believe that the inconsistencies and discordant results reported by the above investigators with the radiation technique can be explained by the fact that no consideration was given to skin temperature. In other words, increases in pain thresholds were only alterations in the apparent pain thresholds. Our results have shown that aspirin, amphetamine sulphate, and antihistamines have no analgesic effect on the actual radiation-pain threshold. Indeed, the statistical analysis suggests a definite increase in pain sensitivity with antihistamines. Only morphine raised the actual threshold. However, in this connexion our experience is in keeping with the observations of Wolff, Hardy, and Goodell (1940), that although the subjects perceived pain they were rather indifferent to it and in addition experienced some difficulty in concentration. The morphine promoted the ability to dissociate pain perception from the anxiety reaction pattern.

Although Hardy and others (1940) realized that among the physical factors influencing the pain threshold were those tending to increase the rate of heat loss from the skin and actually stated that the skin temperature had some influence on the threshold, apparently 11 years elapsed before they considered this important factor experimentally (Hardy and others, 1951). Further, in their recent monograph, Hardy and others (1952b) have not attempted to apply their own "temperature correction factor" to their previous tests with analgesics.

Three comments are relevant. Sonnenschein and Ivy (1949) objected that the experiments of the three originators were carried out only on themselves and without placebo controls. Gregg (1951) main-Э tained that the threshold for pain by the radiation? technique was merely a critical local temperature, found by Whyte (1951), Hardy and others (1951), Cook (1952), and Wertheimer and Ward (1952) to be $46 \cdot 58^{\circ}, 46 \cdot 1^{\circ}, 44 \cdot 9^{\circ}$, and $44 \cdot 1^{\circ} \mathrm{C}$. respectively. 등 Whyte (1951) calculated from extrapolation of the data of Hardy and others that the critical localo temperatures would be $46^{\circ} \mathrm{C}$. for normal subjects, $50^{\circ} \mathrm{C}$. after aspirin, and $54^{\circ}$ after morphine.

We are not denying the analgesic effects of drugs 0 such as aspirin, morphine, and antihistamines, but $-\overrightarrow{-}$ the experiments suggest the impossibility of cor- $-\omega$ relating deep-pain analgesic efficacy with an effect on the superficial radiation pain threshold. In this. respect it should be noted that Lewis (1938), and $\overrightarrow{+}$ more recently Kellgren and McGowan (1948) have demonstrated the dissociation of deep-pain and skin-pain sensibility.

There appear to be the two categories of pain, that arising from exogenous superficial stimulation, not $\vec{\sigma}_{\vec{\sigma}}$ easily modified by analgesics, and that due to endogenous pathological stimulation, the alleviation of which may be brought about by modification of the underlying process.

\section{Summary}

○ृ ज़ ज़

(1) A modification of the thermal radiation method of pain stimulation with fixed intensity an variable exposure times was used in a study of integumentary pain thresholds.

(2) A distinction has been drawn between apparent and actual pain thresholds.

(3) Changes in the apparent radiation pain $\overrightarrow{\bar{O}}$ threshold were observed to be inversely related to alterations in the skin temperature of the area.

(4) Significant interpersonal and day-to-day differences in the actual pain thresholds were found.

(5) No definite elevation of the actual radiation pain threshold was demonstrated after adminis- 3 . tration of aspirin, amphetamine, or antihistamines.

(6) Only morphine showed an analgesic effect, although in this respect the indifference and dis-o sociation produced may be important factors.

(7) Our experience suggests the impossibility of correlating deep-pain analgesic efficiency with effects on the actual radiation pain threshold. O

(8) No significant difference was found between N the range of actual skin radiation pain thresholds inN the rheumatoid arthritis patients studied and in the ${ }_{\sigma}^{\omega}$ normal group.

We are indebted to Professor S. J. Hartfall, whose patients we studied, for his constant interest and en-? couragement. We also thank Mr. J. D. Sargan, M.A., 
for the statistical analysis, and Miss B. G. Lawes for her technical assistance.

\section{REFERENCES}

Andrews, H. L. (1942). J. Amer. med. Ass., 120, 525.

(1943a). J. clin. Invest., 22, 511.

(1943b). Ibid., 22, 517 .

Bigelow, N., Harrison, I., Goodell, H., and Wolf, H. G. (1945). Ibid., 24, 503.

Birren, J. E., Schapiro. H. B., and Miller, J. H. (1950). J. Pharmacol., $100,67$.

Chapman, W. P., Arrowood, J. G., and Beecher, H. K. (1943). J. clin. Invest., 22, 871. and Jones, C. M. (1944). Ibid., 23, 81.

—, Finesinger, J. E., Jones, C. M., and Cobb, S. (1947). Arch. Neurol. Psychiat. (Chicago), 57, 321.

Clausen, J., and King, H. E. (1950). J. Psychol., 30, 299

Cook, H. F. (1952). J. Physiol., 118, 1.

Dodds, E. C., Lawson, W., Simpson, S. A., and Williams, P. C. (1945). Ibid., 104, 47.

Denton, J. E., and Beecher, H. K. (1949). J. Amer. med. Ass., 141, 1051 .

Flodmark, S., and Wramner, T. (1945). Acta physiol. scand., 9, 88

Gregg, E. C.'(1951). J. appl. Physiol., 4, 351.

Gross, E. G., Holland, H. L., and Schueler, F. W. (1948). Ibid. $1,298$.

Hall, K. R. L. (1953). Brit. J. Psychol., 44, 279.

- and Stride, E. (1954). Brit. J. med. Psychol., 27, 48.

Hardy, J. D., and Cattell, McK. (1950). Fed. Proc., 9, 282.

Hardy, J. D., and Cattell, McK. (1950). Fed. Proc., 9, 282. Goodell, H., and Wolff, H. G. (1951). Science, 114, 149. Wolff, H. G., and Goodell, H. (1940). J. clin. Invest., 19, 649 Williams and Wilkins, Baltimore.

Williams and Wilkins, Baltimore.
Hazouri, L. A., and Mueller, A. D. (1950). Arch. Neurol. Psychiat. (Chicago), 64, 607.

Hemphill, R. E., Hall, K. R. L., and Crookes, T. G. (1952). J. ment. Sci., $98,433$.

Ivy, A. C., Goetzl, F. R., and Burrill, D. Y. (1944). War Med., 6,67 .

Kellgren, J. H., and McGowan, A. J. (1948). Clin. Sci., 7, 1.

Kibler, R. F., and Schnaper, H. W. (1950). Amer. J. med. Sci., 220, 199.

Kutscher, A. H., and Chilton, N. W. (1951). J. dent. Res., 30, 822

$\overline{1}, \frac{1}{1952) . ~ A m e r . ~ J . ~ m e d . ~ S c i ., ~ 223, ~} 239$

Kuhn, R. A., and Bromiley, R. B. (1951). J. Pharmacol., 101, 47

Leduc, E. H., and Slaughter, D. (1945). Curr. Res. Anesth., 24, 147.

Lewis, T. (1938). Brit. med. J., 1, 321.

McMurray, G. A. (1950). Arch. Neurol. Psychiat., 64, 650.

Schamp, J. R., and Schamp, H. M. (1946). J. dent. Res., 25, 101.

Schilling, R. F., and Musser, M. J. (1948). Amer. J. med. Sci., 215, 195 .

(1949a). Ibid., 218, 204.
(1949b). Ibid., 218, 207.

Schumacher, G. A., Goodell, H., (1940). Science, 92, 110

Scott, C. C., and Chen, K. K. (1946a). Fed. Proc., 5, 201

_ (1946b). J. Pharmacol., 87, 63.

- Robbins, E. B., and Chen, K. K. (1946). Science, 104, 587

Slaughter, D. (1944). Anaesthesiology, 5, 508.

—, and Gales, J. W. (1942). Fed. Proc., 1, 167.

, and Johnson, T. U. (1944). Quoted by Slaughter (1944), as in manuscript.

-, and Wright, F. T. (1944). Curr. Res. Anesth., 23, 115

Sonnenschein, R. R., and Ivy, A. C. (1949). J. Pharmacol., 97, 308.

Thorp, R. H. (1946). Brit. J. Pharmacol., 1, 113

Thorp, R. H. (1946). Brit. J. Pharmacol,, 1, I13.

Wertheimer, M., and Ward, W. D. (1952).

Wolf, H. G., Hardy, J. D., and Goodell, H. (1940). J. clin. Invest., 19, 659 .

\section{Le seuil de la perception douloureuse de l'irradiation} par rapport aux températures cutanées RÉSUMÉ

(1) Pour étudier le seuil de la douleur cutanée on se servit d'une modification de la méthode d'irradiation thermique, consistant à la stimulation d'intensité fixe et de durée variable.

(2) On établit une distinction entre le seuil apparent et réel de la douleur.

(3) On nota que le seuil douloureux apparent variait en raison inverse de la température cutanée locale.

(4) On trouva des variations significatives du seuil douloureux réel selon le sujet et selon le jour.

(5) On ne décéla pas d'élévation nette du seuil de la perception douloureuse réelle de l'irradiation après l'administration d'aspirine, de phényl-1-amino-2-propane ou d'antihistamines.

(6) Seule la morphine révéla un effet antalgique et même ici l'indifférence et la dissociation auraient pu intervenir.

(7) Nos expériences suggèrent qu'il est impossible de déterminer un rapport entre l'effet sur la perception douloureuse profonde et l'effet sur le seuil réel de la perception douloureuse de l'irradiation.

(8) On ne trouva pas de différence significative entre les arthritiques rhumatismaux et les sujets sains étudiés en ce qui concerne le seuil réel de la perception douloureuse.

El umbral de la percepción dolorosa de la irradiación en relación a temperaturas de la piel Sumario

(1) Se estudió el umbral del dolor cutáneo con una modificación del método de irradiación térmica, consistiendo en la estimulación de intensidad fija y de duración variable.

(2) Se estableció una distincción entre el umbral aparente y real del dolor.

(3) Se notó que el umbral doloroso aparente varia en proporción inversa a la temperatura cutánea local.

(4) Se encontraron variaciones significativas del umbral doloroso real según el tiempo y el sujeto.

(5) No se demostró elevación definida del umbral de la percepción dolorosa real de la irradiación después de la administración de aspirina, amfetamina (fenil-1amino-2-propano) o de antihistamínicos.

(6) Sólo la morfina reveló un efecto analgésico, aunque aquí la indiferencia y la disociación hubieran podido intervenir.

(7) Nuestra experiencia sugiere que no es posible determinar una relación entre el efecto sobre la percepción dolorosa profunda y el efecto sobre el umbral real de la percepción dolorosa de la irradiación.

(8) No se encontró diferencia significativa entre los enfermos con artritis reumatoide y los sujetos sanos estudiados respecto al umbral real de la percepción dolorosa. 